\title{
Trends in Follow-up of Patients Presenting to the Emergency Department with Symptomatic Cholelithiasis
}

\author{
Francesca M. Dimou ${ }^{1,2}$ \\ Deepak Adhikari ${ }^{1}$ \\ Hemalkumar B. Mehta ${ }^{1}$ \\ Taylor S. Riall ${ }^{1,3}$
}

Departments of Surgery, The University of Texas Medical Branch, Galveston, Texas, ${ }^{1}$ the University of South Florida, Tampa, Florida ${ }^{2}$ and the University of Arizona, Tuscon, Arizona $^{3}$

Funding: Supported by grants from the Cancer Prevention Research Institute of Texas Grant \# RP140020, UTMB Clinical and Translational Science Award \#UL1TR000071, NIH T-32 Grant \# 5T32DK007639, and AHRQ Grant \# 1R24HS022134

\section{Corresponding Author:}

Taylor S. Riall, M.D., Ph.D.

Professor, Department of Surgery

University of Arizona

1501 N Campbell Ave, Rm 4237b

PO Box 245131

Tucson, AZ 85724

Email: tsriall@surgery.arizona.edu 


\begin{abstract}
INTRODUCTION: Fewer than 25\% of Medicare beneficiaries presenting with symptomatic cholelithiasis undergo elective cholecystectomy. To better understand underuse of cholecystectomy, we examined physician follow-up patterns after emergency department (ED) visits for symptomatic gallstones.

METHODS: We used 100\% Texas Medicare claims (2001-2010) to identify patients $\geq 66$ years who presented to the ED with symptomatic cholelithiasis and were discharged home without cholecystectomy. Timing of outpatient physician visits after ED discharge and rates of emergent cholecystectomy based on physician follow-up patterns were compared.
\end{abstract}

RESULTS: 11,126 patients presented to the ED with symptomatic cholelithiasis and were discharged without cholecystectomy. After discharge, 5,327 patients (47.9\%) had an outpatient surgeon visit; $29.0 \%$ saw another physician and never saw a surgeon, and $23.1 \%$ never saw a physician. $68.2 \%$ of patients who saw a surgeon underwent elective cholecystectomy. $8.3 \%$ of patients who saw a surgeon, $14.6 \%$ of patients who saw other physicians and no surgeon, and $77.6 \%$ of patients who never saw any physician required emergent hospitalization $(\mathrm{p}<0.0001)$. For people who did not see a physician, mean time to emergent hospitalization was 7.5 days (median=2 days); $95.9 \%$ presented within 2 weeks after their initial presentation.

CONCLUSION: Fewer than half of patients were evaluated by a surgeon after an initial ED visit for symptomatic gallstones. Patients who did not have physician follow-up were most likely to require emergent cholecystectomy, suggesting inappropriate ED discharge and highlighting the need for timely follow-up. Early outpatient surgical consultation is 
critical in determining appropriateness for cholecystectomy and avoiding emergent cholecystectomy in older patients with symptomatic gallstones. 


\section{INTRODUCTION}

The prevalence of gallstone disease increases with age. Twenty to thirty percent of people older than 60 years have gallstones, ${ }^{1,2}$ and up to $80 \%$ of institutionalized patients older than 90 have been found to have gallstones. ${ }^{3}$ Guidelines developed by the Society of American Gastrointestinal and Endoscopic Surgeons (SAGES) recommend elective cholecystectomy for patients with symptomatic gallstone disease, with few absolute or relative contraindications. ${ }^{4}$ Yet, despite these guidelines and the increasing prevalence of gallstones in the elderly population, older patients are less likely undergo definitive treatment with cholecystectomy. ${ }^{5,6}$ Previous work by our group demonstrated that fewer than $25 \%$ of Medicare beneficiaries undergo elective cholecystectomy for gallstone disease. ${ }^{7}$ Furthermore, receipt of cholecystectomy was independent of a patient's risk of developing gallstone-related complications. ${ }^{7,8}$

Consequently, older patients are more likely to present with complicated gallstone disease including gallbladder perforation, gangrenous cholecystitis, and emphysematous cholecystitis. ${ }^{9,10}$ Once these complications occur in the elderly, mortality and morbidity increase dramatically. ${ }^{11-14}$ The reluctance to perform elective cholecystectomy in elderly patients is likely multifactorial and includes concerns about increased morbidity, mortality, and length of hospital stay due to the comorbidities and frailty commonly seen in this population. ${ }^{15,16}$ In addition, it is difficult for physicians to predict the risk of developing gallstone-related complications and balance this risk with operative risk at the time of decision making. However, studies have shown that laparoscopic cholecystectomy is a safe procedure in this subset of patients despite slightly increased lengths of stay and increased conversion to open procedures. ${ }^{13,17,18}$ 
Based on the previously developed PREOP-Gallstones risk prediction model, ${ }^{8}$ patients who presented to the emergency department for their initial episode of symptomatic cholelithiasis and were sent home without a cholecystectomy were at high risk for future gallstone-related complications. ${ }^{7}$ The objective of our study was to better understand the underuse of elective cholecystectomy in these high-risk older patients seen in an ED for their gallstones by examining physician follow-up patterns after a patient's initial presentation to the emergency department (ED) with a symptomatic episode. Patient outcomes were compared based on physician follow-up patterns.

\section{METHODS}

The study was reviewed by the institutional review board at the University of Texas Medical Branch, Galveston, TX. As the study involved analysis of secondary data, it was not considered human subjects research and was granted exemption.

\section{Data Source}

This study used enrollment and claims data for $100 \%$ of Texas Medicare beneficiaries from 2001 to 2010. Demographic and enrollment data were obtained from the Denominator file. The Medicare Provider Analysis and Review file (MEDPAR) was used to obtain inpatient hospital admission claims. Outpatient claims and claims submitted by non-institutional providers were obtained from the Outpatient Standard Analytic File (OUTSAF) and Carrier Standard Analytic File (SAF).

\section{Cohort Selection}

We identified all patients who presented to the emergency department with symptomatic cholelithiasis and were discharged without admission or cholecystectomy. ${ }^{19}$ We used the following inclusion criteria to derive the study cohort (Figure 1): 1) patients 
with symptomatic gallstone disease identified using International Classification of Disease, $9^{\text {th }}$ Edition (ICD-9) codes (Table 1); 2) age 66 and older; 3) seen in the emergency department for their initial visit; 4) did not require hospital admission and/or cholecystectomy (identified using Current Procedural Terminology codes; Table 1); and 5) continuously enrolled in Medicare Part A and Part B for at least 12 months before and two years after the first ED visit, without HMO coverage.

Identifying Physician Follow-up Patterns

Using Evaluation and Management codes (E\&M), physician outpatient visits were identified from the OUTSAF or carrier SAF (Table 1). Physicians were classified as surgeons, primary care physicians (PCP), and other physician specialties. We evaluated the trajectory of care by examining physician visits, subsequent elective cholecystectomy, emergent hospital admission, and emergent cholecystectomy in the two years after ED discharge. A patient was considered to have had an elective cholecystectomy if evaluated by a surgeon on an outpatient basis or underwent elective cholecystectomy; if a patient had a code for elective cholecystectomy, but did not have a E\&M code for a surgeon visit they were classified as having seen a surgeon given only elective operations can be done if scheduled with a surgeon. Patients without an E\&M code were identified as having no outpatient physician follow-up.

\section{Outcomes}

We evaluated rates of elective or emergent/urgent cholecystectomy rates in patients who were seen by: 1) a surgeon (either initially or after seeing a PCP or other specialist), 2) seen by a PCP or other physician only, and 3) or not seen by a physician in the outpatient setting using ICD-9 and CPT procedure codes (Table 1). Hospital 
admission patterns for gallstone-related complications were also identified within the three physician categories above. Rates of cholecystectomy and hospital admission were compared between physician categories. Postoperative complications and 30-day mortality rates were identified and compared in patients who underwent elective cholecystectomy versus emergent.

Statistical Analysis

Descriptive statistics were done to compare patients who were evaluated by a surgeon versus those who were not. Chi-square and t-tests were done to compare categorical and continuous variables, respectively.

\section{RESULTS}

\section{Cohort characteristics}

Overall, 11,126 patients presented to the ED with symptomatic cholelithiasis and were discharged home without admission or cholecystectomy. Overall patient characteristics are summarized in Table $2 ; 24.0 \%(\mathrm{~N}=2,670)$ were aged $66-69$ years and only $11.9 \%(\mathrm{~N}=1,327)$ of patients were older than 85 years. The greatest proportion of patients had a comorbidity index of 3 or greater $(33.8 \%$; $=3,757)$. At ED presentation, $56.8 \%(\mathrm{~N}=6,323)$ of patients had a diagnosis of biliary colic, $31.7 \%(\mathrm{~N}=3,526)$ had acute cholecystitis, 4.2\% ( $\mathrm{N}=468)$ had common bile duct stones, and 7.3\% $(\mathrm{N}=809)$ had gallstone pancreatitis.

\section{Physician Visits}

Physician follow-up and trajectory of care are shown in Figure 2. Within the twoyear study period, 5,327 (47.9\%) patients had an outpatient surgeon visit of which, 2,551 $(22.9 \%)$ went directly to a surgeon following their incident episode and 2,776 saw 
another physician first (Figure 2). Out of 11,126, 3,223 patients $(29.0 \%)$ saw a PCP or other specialist, but never saw a surgeon, and 2,576 (23.2\%) never saw any physician after the incident episode.

\section{Outcomes:}

In the overall cohort, emergent hospitalization or cholecystectomy was required in 2,914 patients (Surgeon: $N=443$; Other physician/No surgeon: $N=471$; No physician: $\mathrm{N}=2000$ ); 3,634 patients underwent an elective procedure, and 4,578 (Surgeon: $\mathrm{N}=1,250$; Other physician/No surgeon: $\mathrm{N}=2,752$; No physician: $\mathrm{N}=576$ ) had no further gallstonerelated acute events and did not undergo cholecystectomy (Figure 2, Table 3).

Of the 5,327 patients who saw a surgeon, $68.2 \%$ underwent an elective operation. Eight percent $(8.3 \%)$ of patients who saw a surgeon required emergent cholecystectomy and/or emergent hospital admission; 23.5\% never underwent an operation or had an emergent gallstone-related hospitalization.

$5,799(52.1 \%)$ patients never saw a surgeon. In this group of patients, $42.6 \%$ $(\mathrm{N}=2,471)$ required emergent cholecystectomy and/or hospitalization and another $9 \%$ $(\mathrm{N}=522)$ had additional ED visits without admission or cholecystectomy. In the 3,223 patients $(29.0 \%)$ who saw primary care physicians or other specialist, but never saw a surgeon, emergent hospitalization or cholecystectomy was required in $14.6 \% ; 85.4 \%$ never underwent an operation or required an emergent hospitalization (Figure 2, Table 3).

In the 2,576 patients who never saw any physician, $77.6 \%(\mathrm{~N}=2,000)$ of patients required an emergent hospitalization or cholecystectomy. When comparing emergent operation and/or gallstone-related emergent admission rates between surgeons, other 
physicians, and no physician follow-up statistical significance was achieved (8.3\% vs. $14.6 \%$ vs. $77.6 \% ; \mathrm{p}<0.0001$ ) (Table 3 ).

Overall complications following cholecystectomy were more frequent in patients who underwent an emergent cholecystectomy versus elective (41.0\% versus $19.4 \%$; $\mathrm{p}<0.0001)$. When comparing specific postoperative complications, all were significantly higher in patients who underwent an emergent cholecystectomy, with the exception of surgical site infection (Table 4). Perioperative mortality was significantly higher in patients who underwent an emergent cholecystectomy versus elective cholecystectomy

(Table $4,3.8 \%$ vs. $0.9 \%$; $\mathrm{p}<0.0001$ ).

Time to physician visit/emergency surgery

In patients who saw a surgeon, the mean time to an elective operation was 42 days (median=13 days). For patients who saw any physician, the mean time to follow-up after the incident episode was 29.7 days (median 7.0 days). In patients who required and emergent cholecystectomy, the median time from ED discharge to emergent cholecystectomy was 43.5 days (mean $=150.6$ days $)$ in those who saw a surgeon, 19.0 days (mean $=94.0$ days) in the other physician group and 2 days (mean $=7.4$ days) in those who never saw a physician. ( $\mathrm{p}<0.0001$ comparing means). For patient who did not see a physician and required emergent hospitalization and/or cholecystectomy $(\mathrm{N}=2,000)$, 95.9\% re-presented within two weeks of their initial ED presentation (Figure 3). In patients who required emergent hospitalization within a week after their initial presentation, $32.3 \%$ had a diagnosis other than biliary colic. Factors predicting elective and emergent hospitalization 
With increasing age, rates of elective cholecystectomy decreased (43.9\% 66-69 vs. $13.6 \%>85$ years) and rates of emergent cholecystectomy increased (23.1\% 66-69 years vs. $28.1 \%>85$ years) (Table 5).

Despite being at higher risk for subsequent gallstone-related events, patients who presented with biliary colic were most likely to undergo an elective operation (35.6\%). Patients who presented with a complicated initial episode including acute cholecystitis (30.8\%), common duct stones (28.4\%), and gallstone pancreatitis were least likely to undergo an elective cholecystectomy (20.5\%; Table 5); this lead to higher rates of emergency operations or hospitalizations in those who presented with a complicated episode (gallstone pancreatitis: 46.8\%; common duct stones: $35.5 \%$; acute cholecystitis: 37.1\%; biliary colic: $16.8 \%$, Table 5).

Using the PRE-OP Gallstones nomogram to predict the 2-year risk of gallstonerelated acute hospitalization or emergent cholecystectomy, the average risk of the entire cohort was $41.9 \%$. Patients who did not see any physician had an average predicted risk of $51.3 \%$ compared to $39.0 \%$ risk in those who saw a physician but no surgeon. The 2 year risk in those who saw a surgeon was $39.2 \%$.

\section{DISCUSSION}

Our study is the first to describe the follow-up patterns in older patients after an initial episode of symptomatic gallstones requiring emergency department visit. It highlights the importance of timely outpatient follow-up in this vulnerable population in order to prevent emergent gallstone-related admission and cholecystectomy. Fewer than $50 \%$ of Medicare beneficiaries saw a surgeon following their initial ED visit. This low rate of outpatient follow-up is, in part, due to the timeliness of follow-up given that in 
those who did not see any physician, emergent hospitalization of cholecystectomy occurred very shortly after their initial presentation. When patients did see a physician, patient selection was appropriate as emergency cholecystectomy rates were far lower compared to those who did not see any physician and the lowest emergent rates occurred when patients were evaluated by a surgeon. Based on our data, early outpatient surgical consultation is critical in determining appropriateness for cholecystectomy and avoiding emergent cholecystectomy in older patients with symptomatic gallstones.

As we move to population health model in healthcare, ideally surgeons would perform cholecystectomy in patients at the highest risk of developing complications and minimize cholecystectomy in those at lowest risk when symptoms are minimally impacting their quality of life. Our group previously established the PREOP-Gallstones nomogram that predicted gallstone-related complications in older patients following their initial presentation of symptomatic cholelithiasis. ${ }^{11}$ Contrary to the idea of treatment based on risk, receipt of cholecystectomy was independent of model-derived risk. ${ }^{7,11}$ Consistent with the PREOP-Gallstones risk prediction model, patients in this cohort had a high risk of subsequent gallstone related emergent events, with an average risk of $42 \%$. In the $52 \%$ of people who did not undergo surgical evaluation and elective cholecystectomy, $43 \%$ required emergent cholecystectomy and/or hospitalization and another $9 \%$ had additional ED visits without admission or cholecystectomy.

Our study identifies two factors that contribute to underuse of cholecystectomy in the older patients discharged from the ED without cholecystectomy and at high risk for gallstone-related complications: 1) lack of surgical evaluations and 2) lack of timely follow-up. Many may have been scheduled for surgical follow-up but required emergent 
admission before this occurred. Others were likely never referred. Even those seeing primary care physicians or other specialists had higher rates of emergent gallstone-related events compared to those seeing a surgeon, highlighting the need for surgical evaluation. In the 2,000 patients who didn't see a physician and required emergent cholecystectomy, the median time to emergent hospitalization was only two days, with $96 \%$ of patients presenting for emergent management at two weeks. The subset of patients who never got to see a physician had a model-predicted risk of acute gallstone-related events of $>50 \%$. This suggests inappropriate discharge from the ED in a subset of these patients, and also highlights the fact that timely follow-up is essential. Many in this group did not see a physician because they developed complications before this could occur. Our data suggest that model-predicted risk can be used to further risk-stratify patients and guide the decision to admit them for cholecystectomy or ensure timely follow-up.

These data provide evidence for developing protocols for patients deemed highrisk for complications as to ensure they receive early follow-up. At different facilities the reasons for lack of surgical evaluation may differ and may include poor discharge planning with no or inadequate instructions for follow-up, lack of timely surgeon availability, reluctance of primary care physicians to refer to surgeons, and many other reasons. Hospitals should evaluate their own follow-up patterns and tailor interventions to address the problems identified in order to provide timely surgeon follow-up. ${ }^{20}$

Despite studies supporting cholecystectomy in elderly patients, there remains a gap in the system. Those who never saw a surgeon were at significant risk of experiencing gallstone-related complications, and patients without any follow-up at were at greatest risk of such complications. Based on the nomogram, these patients had a $51 \%$ 
risk of a 2-year gallstone related complication and are patients that should have received the timeliest follow-up. While we cannot identify whether patients had schedule appointments, it is clear that follow-up was not soon enough. Moreover, patients who did not see a surgeon were older and had more co-morbidities, further demonstrating those at higher risk of gallstone-related complications did not only see a physician soon enough, but these patients required early emergent hospitalization.

When emergent cholecystectomy was necessary, patients were more likely to postoperative complications perioperative mortality were higher compared to those who underwent an elective operation. The importance of identifying certain patients as highrisk and ensuring timely physician follow-up cannot be emphasized enough especially when considering patient morbidity, cost, and length of stay associated with an emergent operation and such outcomes being preventable in many of these patients.

The major limitation in our study is we cannot make conclusions as to why patients did not see a physician and/or surgeon. Access to medical care is not likely given patients were insured under Medicare with continuous enrollment; however, we cannot determine if patients had an appointment or there was lack of surgeon availability resulting in lack of follow-up. Physicians may be referring patients for surgical evaluation, but patients may not be able to make an appointment or choose not to follow these recommendations. In patients who did see a surgeon, but did not undergo an elective cholecystectomy, we cannot identify the reasons. The lower rates of emergent cholecystectomy suggest improved patient selection relative to the other two groups, but also suggest room for improvement. The surgeon may have counseled or recommended surgical intervention to the patient, but the patient chose observation. Or the surgeon may 
have deemed the patient too high risk for surgical intervention when all clinical factors were considered.

\section{CONCLUSIONS}

In conclusion, fewer than half of patients are referred to and evaluated by surgeons after an initial emergency department visit for symptomatic gallstones. Over three quarters of patients who did not have any outpatient physician follow-up required urgent or emergent gallstone-related admission and/or cholecystectomy secondary to them requiring emergent hospitalization very shortly after their initial presentation and precluding them from outpatient follow-up. Therefore, not only is outpatient surgical consultation critical in these patients, it is essential in patients who are identified as high risk, which includes all patients who present to the emergency department. Establishing protocols to ensure rapid and appropriate follow-up in these patients may help prevent future gallstone-related complications. Incorporation of a risk model and education of all physicians who encounter these patients may help improve outcomes by aligning treatment with risk, thereby reducing gallstone-related complications. Moreover, it has the potential to reduce the burden on the healthcare system by reducing gallstone-related admissions for patients who repeatedly require it. 


\section{REFERENCES}

1. Bergman S, Sourial N, Vedel I, et al. Gallstone disease in the elderly: are older patients managed differently? Surgical endoscopy. Jan 2011;25(1):55-61.

2. Lirussi F, Nassuato G, Passera D, et al. Gallstone disease in an elderly population: the Silea study. European journal of gastroenterology \& hepatology. May 1999;11(5):485-491.

3. Ratner J, Lisbona A, Rosenbloom M, Palayew M, Szabolcsi S, Tupaz T. The prevalence of gallstone disease in very old institutionalized persons. Jama. Feb 20 1991;265(7):902-903.

4. Overby DW, Apelgren KN, Richardson W, Fanelli R, Society of American G, Endoscopic S. SAGES guidelines for the clinical application of laparoscopic biliary tract surgery. Surgical endoscopy. Oct 2010;24(10):2368-2386.

5. Arthur JD, Edwards PR, Chagla LS. Management of gallstone disease in the elderly. Annals of the Royal College of Surgeons of England. Mar 2003;85(2):9196.

6. Siegel JH, Kasmin FE. Biliary tract diseases in the elderly: management and outcomes. Gut. Oct 1997;41(4):433-435.

7. Riall TS, Adhikari D, Parmar AD, et al. The risk paradox: use of elective cholecystectomy in older patients is independent of their risk of developing complications. Journal of the American College of Surgeons. Apr 2015;220(4):682-690.

8. Parmar AD, Sheffield KM, Adhikari D, et al. PREOP-Gallstones: A Prognostic Nomogram for the Management of Symptomatic Cholelithiasis in Older Patients. Annals of surgery. Jul 282014.

9. Bedirli A, Sakrak O, Sozuer EM, Kerek M, Guler I. Factors effecting the complications in the natural history of acute cholecystitis. Hepatogastroenterology. Sep-Oct 2001;48(41):1275-1278.

10. Morrow DJ, Thompson J, Wilson SE. Acute cholecystitis in the elderly: a surgical emergency. Archives of surgery. Oct 1978;113(10):1149-1152.

11. Parmar AD, Sheffield KM, Adhikari D, et al. PREOP-Gallstones: A Prognostic Nomogram for the Management of Symptomatic Cholelithiasis in Older Patients. Annals of surgery. Jun 2015;261(6):1184-1190.

12. Riall TS, Zhang D, Townsend CM, Jr., Kuo YF, Goodwin JS. Failure to perform cholecystectomy for acute cholecystitis in elderly patients is associated with increased morbidity, mortality, and cost. Journal of the American College of Surgeons. May 2010;210(5):668-677, 677-669.

13. Fukami Y, Kurumiya Y, Mizuno K, Sekoguchi E, Kobayashi S. Cholecystectomy in octogenarians: be careful. Updates in surgery. Dec 2014;66(4):265-268.

14. Lupinacci RM, Nadal LR, Rego RE, et al. Surgical management of gallbladder disease in the very elderly: are we operating them at the right time? European journal of gastroenterology \& hepatology. Mar 2013;25(3):380-384.

15. Pavlidis TE, Marakis GN, Symeonidis N, et al. Considerations concerning laparoscopic cholecystectomy in the extremely elderly. Journal of 
laparoendoscopic \& advanced surgical techniques. Part A. Feb 2008;18(1):5660.

16. Brunt LM, Quasebarth MA, Dunnegan DL, Soper NJ. Outcomes analysis of laparoscopic cholecystectomy in the extremely elderly. Surgical endoscopy. Jul 2001;15(7):700-705.

17. Caglia $\mathrm{P}$, Costa $\mathrm{S}$, Tracia A, et al. Can laparoscopic cholecystectomy be safety performed in the elderly? Annali italiani di chirurgia. Jan-Feb 2012;83(1):21-24.

18. Bingener J, Richards ML, Schwesinger WH, Strodel WE, Sirinek KR. Laparoscopic cholecystectomy for elderly patients: gold standard for golden years? Archives of surgery. May 2003;138(5):531-535; discussion 535-536.

19. Kaskie B, Obrizan M, Cook EA, et al. Defining emergency department episodes by severity and intensity: A 15-year study of Medicare beneficiaries. BMC health services research. 2010;10:173.

20. Ambe PC, Weber SA, Christ H, Wassenberg D. Primary cholecystectomy is feasible in elderly patients with acute cholecystitis. Aging clinical and experimental research. Apr 242015. 
Table 1. The International Classification of Diseases, 9th Revision, Clinical Modification (ICD-9-CM) and Current Procedural Terminology (CPT) codes to identify patients and procedures

\begin{tabular}{|c|c|}
\hline & ICD-9-CM/CPT or E\&M Code \\
\hline \multicolumn{2}{|l|}{ Initial Diagnosis } \\
\hline Gallstone Pancreatitis & $\begin{array}{l}577.0 \text { and any secondary diagnosis starting with } \\
574^{*} / 575^{*} \text { OR } 574^{*} \text { or } 575^{*} \text { and a secondary } \\
\text { diagnosis code for pancreatitis }\end{array}$ \\
\hline Acute calculous cholecystitis & $\begin{array}{l}574.0(574.00,574.01), 574.1(574.10,574.11), \\
575.0,575.1,575.2,575.3,575.4\end{array}$ \\
\hline Common bile duct stones & $\begin{array}{l}574.3(573.20,574.31), 574.4(574.40,574.41), \\
574.5(574.50,574.51), 574.6(574.60,574.61), \\
574.7(574.70,574.71), 574.8(574.80,574.81), \\
574.9(574.90,574.91)\end{array}$ \\
\hline Biliary colic/biliary dyskinesia & $575.8,574.2(574.20,574.21)$ \\
\hline \multicolumn{2}{|l|}{ Laparoscopic cholecystectomy } \\
\hline Laparoscopic cholecystectomy & 51.23; CPT: 47562 \\
\hline Cholecystectomy with cholangiography & 51.21; CPT 47563 \\
\hline $\begin{array}{l}\text { Cholecystectomy with exploration of } \\
\text { common duct }\end{array}$ & 51.24; СРT: 47564 \\
\hline Cholecystoenterostomy & CPT: 47570 \\
\hline Unlisted laparoscopy procedure, biliary tract & CPT: 47579 \\
\hline \multicolumn{2}{|l|}{ Postoperative Complications } \\
\hline Surgical Site Infection & $998.5,998.51,998.59$ \\
\hline Urinary Tract Infection & $\begin{array}{l}1122,590.1,590.11,5903,590.8,590.81,595.0, \\
595.3,599.0,99664\end{array}$ \\
\hline Pneumonia & $\begin{array}{l}0391,1124,1179,1363,46619,480.0,480.1, \\
480.2,480.3,480.8,480.9,481,481.0,482.0, \\
482.1,482.2,482.30,482.31,482.32,482.39 . \\
482.40,482.41,482.42,482.49,482.81,482.82, \\
482.83,482.84,482.89,482.9,483.0,483.1, \\
483.8,484.1,484.3,484.5,484.6,484.7,484.8, \\
487.0,486,485,4841,4846,4847,485,486, \\
4870,507 *, 5130,5168,99731,99739\end{array}$ \\
\hline Sepsis & $\begin{array}{l}038,038.1,038.2,038.3,038.4,038.8,038.9 \\
78552,99591,99592,9980,99859,99931\end{array}$ \\
\hline Deep Vein Thrombosis & $\begin{array}{l}451.1,451.2,451.8,451.9,453.4,453.41 .453 .42 \text {, } \\
453.8,453.9\end{array}$ \\
\hline Pulmonary Embolism & $415.1,415.11,415.12,415.19$ \\
\hline Myocardial Infarction: & $\begin{array}{l}410,410.0,410.00,410.01,410.02,410.10 \\
410.11,410.12,410.20,410.21,410.22,410.30 \\
410.40,410.41,410.42,410.50,410.51,410.52 \\
410.60,410.61,410.62,410.70,410.71,410.72 \\
410.80,410.82,410.90 .410 .91,410.92\end{array}$ \\
\hline Other Surgical Complications Related to & $998.0,998.1 *, 998.2,998.3 *, 998.4,998.6,998.7$ \\
\hline
\end{tabular}




\begin{tabular}{|l|l|}
\hline Laparoscopic Cholecystectomy & $998.8,998.9,997.4,997.5$, and 997 \\
\hline Follow-Up Visit Type & \\
\hline New patient & $99201-99205$ \\
\hline Established patient & $99211-99215$ \\
\hline Office consultation & $99241-99245$ \\
\hline & \\
\hline Specialty & \\
\hline Primary Care & $01,08,11,38,84$ \\
\hline Surgeon & $02,24,28,33,77,78,91$ \\
\hline
\end{tabular}

Table 2. Comparison of Demographics in Patients based on Physician Follow-Up Patterns

\begin{tabular}{|l|c|c|c|c|c|}
\hline & Overall Cohort & Surgeon & PCP/Other & No Physician & p-value \\
\hline Age Group & $\mathrm{N}($ column \%) & $\mathrm{N}($ row \%) & $\mathrm{N}($ row \%) & N (row \%) & \\
\hline $66-69$ & $2,670(24.0)$ & $1,552(58.1)$ & $645(24.2)$ & $473(17.7)$ & $<0.0001$ \\
\hline $70-75$ & $3,272(29.4)$ & $1,747(53.4)$ & $852(26.0)$ & $673(20.6)$ & \\
\hline $76-85$ & $3,857(34.7)$ & $1,655(42.9)$ & $1,209(31.4)$ & $993(25.7)$ & \\
\hline $85+$ & $1,327(11.9)$ & $373(28.1)$ & $517(39.0)$ & $437(32.9)$ & \\
\hline Gender & & & & & \\
\hline Female & $6,542(58.8)$ & $3,138(47.9)$ & $1,979(30.3)$ & $1,425(21.8)$ & $<0.0001$ \\
\hline Male & $4,584(41.2)$ & $2,189(47.8)$ & $1,244(27.1)$ & $1,151(25.1)$ & \\
\hline Ethnicity & & & & & \\
\hline Caucasian & $9,022(81.1)$ & $4,441(49.2)$ & $2,517(27.9)$ & $2,064(22.9)$ & $<0.0001$ \\
\hline African American & $885(8.0)$ & $358(40.5)$ & $324(36.6)$ & $203(22.9)$ & \\
\hline Hispanic & $973(8.7)$ & $441(45.3)$ & $290(29.8)$ & $242(24.9)$ & \\
\hline Other & $246(2.2)$ & $87(35.4)$ & $92(37.4)$ & $67(27.2)$ & \\
\hline Comorbidity Index & & & & & \\
\hline 0 & $2,693(24.2)$ & $1,403(52.1)$ & $667(24.8)$ & $623(23.1)$ & $<0.0001$ \\
\hline 1 & $2,555(23.0)$ & $1,315(51.5)$ & $717(28.1)$ & $523(20.4)$ & \\
\hline 2 & $2,121(19.0)$ & $1,049(49.4)$ & $610(28.8)$ & $462(21.8)$ & \\
\hline$>=3$ & $3,757(33.8)$ & $1,560(41.5)$ & $1,229(32.7)$ & $968(25.8)$ & \\
\hline Diagnosis & & & & & \\
\hline Biliary Colic & $6,323(56.8)$ & $3,393(53.7)$ & $2,110(33.4)$ & $820(12.9)$ & $<0.0001$ \\
\hline Acute Cholecystitis & $3,526(31.7)$ & $1,496(42.4)$ & $789(22.4)$ & $1,241(35.2)$ & \\
\hline CBD Stones & $468(4.2)$ & $197(42.1)$ & $127(27.1)$ & $144(30.8)$ & \\
\hline Gallstone Pancreatitis & $809(7.3)$ & $241(29.8)$ & $197(24.3)$ & $371(45.9)$ & \\
\hline
\end{tabular}


Table 3. Comparison of Patient Outcomes Following Initial Emergency Department Visit for Symptomatic Cholelithiasis based on Physician Follow-up

\begin{tabular}{|l|c|c|c|c|}
\hline & $\begin{array}{c}\text { Elective Cholecystectomy, } \\
\text { N (\%) }\end{array}$ & $\begin{array}{c}\text { Emergent Hospitalization or } \\
\text { Cholecystectomy, N (\%) }\end{array}$ & $\begin{array}{c}\text { No } \\
\text { Cholecystectomy, } \\
\text { N (\%) }\end{array}$ & p-value \\
\hline Surgeon & $3,634(68.2)$ & $443(8.3)$ & $1,250(23.5)$ & \\
\hline PCP/Other & 0 & $471(14.6)$ & $2,752(85.4)$ & $<0.0001$ \\
\hline None & 0 & $2,000(77.6)$ & $576(22.4)$ & \\
\hline
\end{tabular}

Table 4. Postoperative complications and 30-day mortality in patients who underwent an elective cholecystectomy versus emergent cholecystectomy

\begin{tabular}{|l|c|c|c|}
\hline & $\begin{array}{c}\text { Elective } \\
\text { Cholecystectomy N (\%) }\end{array}$ & $\begin{array}{c}\text { Emergent } \\
\text { Cholecystectomy N(\%) }\end{array}$ & p-value \\
\hline Any Complication & $705(19.4)$ & $1,055(41.0)$ & $<0.0001$ \\
\hline Surgical Site Infection & $50(1.4)$ & $47(1.8)$ & 0.16 \\
\hline Urinary Tract Infection & $179(4.9)$ & $284(11.0)$ & $<0.0001$ \\
\hline Pneumonia & $88(2.4)$ & $206(8.0)$ & $<0.0001$ \\
\hline Sepsis & $103(2.8)$ & $226(8.8)$ & $<0.0001$ \\
\hline Deep Vein Thrombosis & $29(0.8)$ & $69(2.7)$ & $<0.0001$ \\
\hline Pulmonary Embolism & $19(0.5)$ & $31(1.2)$ & 0.003 \\
\hline Myocardial Infarction & $33(0.9)$ & $56(2.2)$ & $<0.0001$ \\
\hline $\begin{array}{l}\text { Other Surgical } \\
\begin{array}{l}\text { Complications Related to } \\
\text { Cholecystectomy }\end{array}\end{array}$ & $159(4.4)$ & $162(6.3)$ & $<0.0001$ \\
\hline 30-day Mortality & & & \\
\hline
\end{tabular}

Table 5. Comparison of Elective Cholecystectomy versus Emergent

Cholecystectomy/ Hospitalization Based on Age Group and Initial Diagnosis

\begin{tabular}{|c|c|c|c|c|}
\hline & $\begin{array}{c}\text { Elective Cholecystectomy, } \\
\text { N (\%) }\end{array}$ & $\begin{array}{c}\text { Emergent } \\
\text { Cholecystectomy, N (\%) }\end{array}$ & $\begin{array}{c}\text { No Cholecystectomy, } \\
\text { N (\%) }\end{array}$ & p-value \\
\hline Age Group & & & & \\
\hline $66-69$ & $1,172(43.9)$ & $618(23.1)$ & $880(33.0)$ & \\
\hline $70-75$ & $1,240(37.9)$ & $803(24.5)$ & $1,229(37.6)$ & $<0.0001$ \\
\hline $75-85$ & $1,042(27.0)$ & $1,120(29.0)$ & $1,695(44.0)$ & \\
\hline$>85$ & $180(13.6)$ & $373(28.11)$ & $774(58.33)$ & \\
\hline Diagnosis & & & & \\
\hline Biliary colic & $2,249(35.6)$ & $1,062(16.8)$ & $3,012(47.6)$ & \\
\hline Acute Cholecystitis & $1,086(30.8)$ & $1,307(37.1)$ & $1,133(32.1)$ & $<0.0001$ \\
\hline CBD Stones & $133(28.4)$ & $166(35.5)$ & $169(36.1)$ & \\
\hline Gallstone Pancreatitis & $166(20.5)$ & $379(46.9)$ & $264(32.6)$ & \\
\hline
\end{tabular}




\section{FIGURE LEGENDS}

Figure 1. Cohort selection diagram for patients seen in the emergency department for acute gallstone disease and subsequently discharged without admission and/or cholecystectomy.

Figure 2. Trajectory of follow-up in all patients seen in the emergency department for acute gallstone disease (2001-2010).

Figure 3. Timing of rehospitalization in patients discharged from the emergency department with symptomatic cholelithiasis and who did not see a physician in the follow-up period ( $\mathrm{N}=2,000)$. Mean time to emergent hospitalization was 7.5 days (median $=2$ days). 
Figure 1.

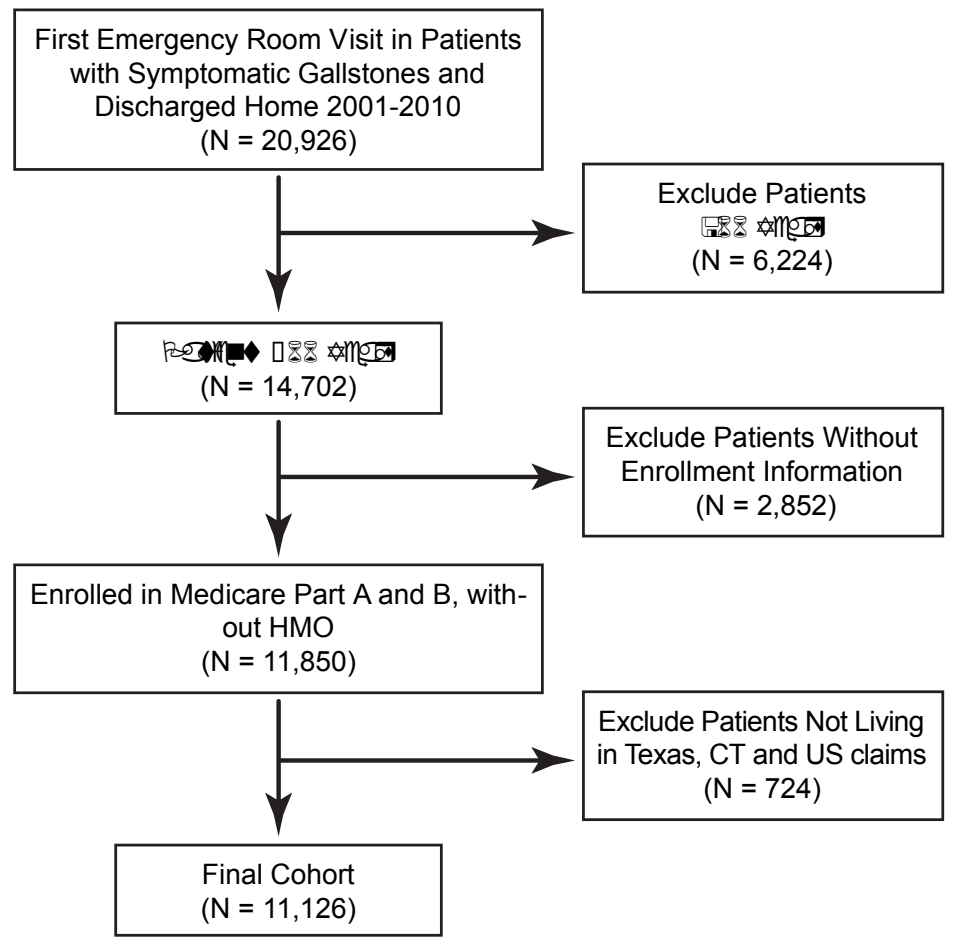


Figure 2.

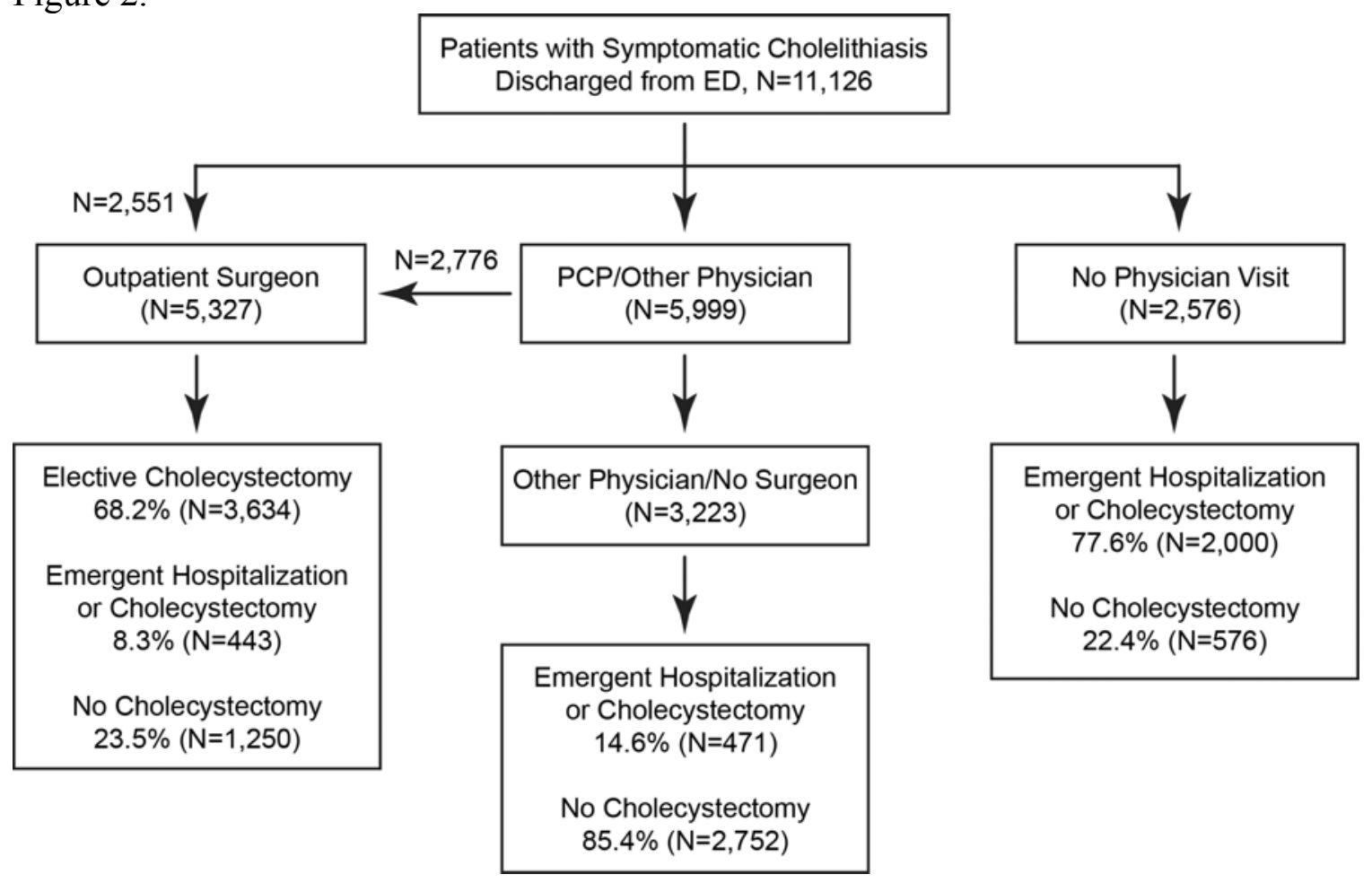


Figure 3.

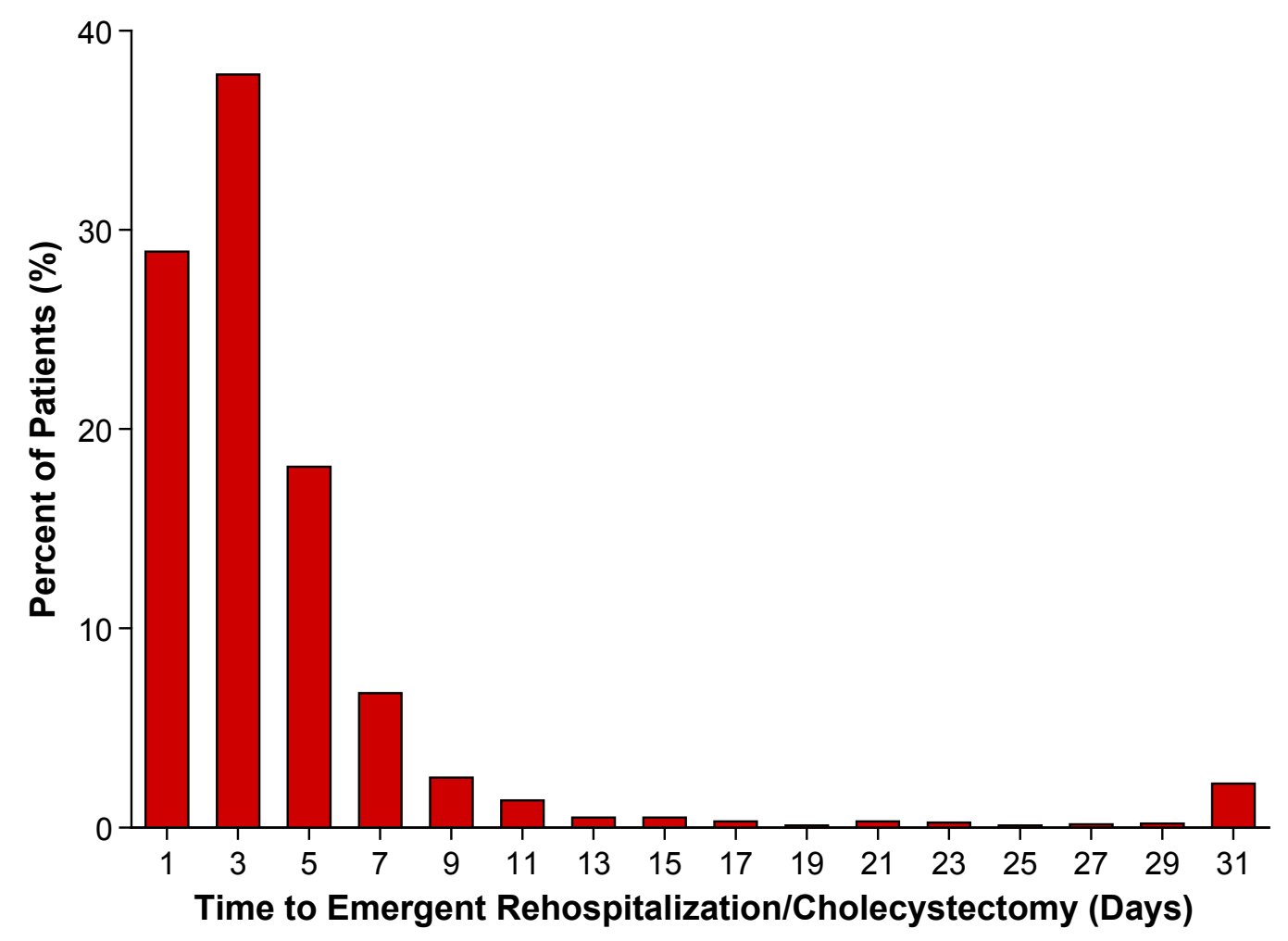

